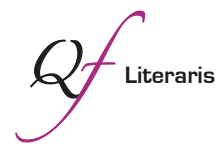

\title{
Dantons Tod, de Georg Büchner: Traducciones y censura en la España franquista
}

\author{
Teresa Julio \\ Universitat de Vic-UCC \\ tjulio@uvic.cat
}

\begin{abstract}
Resumen: A finales de 1834 Georg Büchner empieza a escribir su primera pieza teatral, Dantons Tod. Durante los últimos diez años de la dictadura franquista, es traducida por la editorial Aguilar (1966), G. del Toro (1973) y Edicions Robrenyo (1976). En el presente artículo se analizan los expedientes de censura que se conservan en el Archivo General de la Administración sobre estas traducciones y las repercusiones que la censura ejerció sobre ellas, en el caso en que lo hizo. Se presta especial atención a la polémica traducción de Emilio Romero, que "manipuló" o "versionó" el texto hasta el extremo de figurar como coautor en el volumen publicado por G. del Toro.
\end{abstract}

Palabras clave: Danton; Büchner; censura; traducción.

\begin{abstract}
In late 1834 Georg Büchner began writing his first play, Dantons Tod. During the last ten years of the Francoist dictatorship, Spanish and Catalan translations of Büchner's play were published by Aguilar (1966), G. del Toro (1973) and Edicions Robrenyo (1976). This article analyzes the censors' files kept by the Archivo General de la Administración in connection with these translations and examines the repercussions of any censorship brought to bear on them. Particular attention is paid to Emilio Romero's controversial translation, which "manipulated" or "adapted" the text to the extent that the translator is featured as coauthor in the edition published by G. de Toro.
\end{abstract}

Keywords: Danton; Büchner; censorship; translation.

》 Julio, Teresa. 2015. "Dantons Tod, de Georg Büchner: Traducciones y censura en la España franquista”. Quaderns de Filologia: Estudis Literaris XX: 91-105. doi: 10.7203 /qdfed.20.7530 



\section{Introducción}

Apenas habían trascurrido 45 años del estallido de la Revolución Francesa, acontecimiento que trastocaría todos los supuestos ideológicos de la historia, cuando Georg Büchner se propuso enfrentar dialécticamente a dos de sus protagonistas, Georges Jacques Danton y Maximilien de Robespierre, en una obra en la que se exponían dos concepciones bien distintas del proceso revolucionario. Nace así Dantons Tod, escrita a finales de 1834 y publicada el año siguiente. La obra no se representó hasta 1902, cuando la Vereins Neue Freie Volksbünhe, dirigida por el movimiento obrero alemán, decide vencer todos los obstáculos y montarla en el Belle-Alliance-Theater de Berlín. Esta fecha tan tardía del estreno se explica, por una parte, por la compleja concatenación de los diferentes cuadros escénicos $y$, por otra, por la censura oscurantista que se cernía sobre los pequeños estados alemanes, reacia a cualquier manifestación revolucionaria ${ }^{1}$.

La pieza de Büchner llega a las imprentas españolas en 1966. Y la fecha no es gratuita: estamos en la segunda etapa de la dictadura (19591975), en la que se van a tomar una serie de medidas que suponen no solo el despegue de la economía española, sino también una ligera apertura del régimen que permite mejorar su imagen en el exterior. Los primeros cambios afectan a la remodelación del Gobierno. La sustitución de los veteranos falangistas por los "modernos" tecnócratas no se producirá sin recelos y la oposición interna entre los aperturistas y los más reaccionarios lastrará numerosos proyectos.

Entre los nuevos rostros que llegan al Ministerio de Información y Turismo se encuentra el de Manuel Fraga Iribarne, que en julio de 1962 entra a ocupar dicha cartera en sustitución de Gabriel Arias Salgado. Una de las medidas más polémicas que adopta es la Ley de Prensa e Imprenta, conocida también como la Ley Fraga, aprobada el 18 de marzo de 1966 (BOE núm. 67, 19/03/1966). Esta ley venía a sustituir las de 1883 y 1938, que habían quedado desfasadas y chocaban con la nueva imagen que del régimen se quería imprimir:

La mención de estas fechas pone de relieve la necesidad de adecuar aquellas normas jurídicas a las actuales aspiraciones de la comunidad

\footnotetext{
1 Sobre las representaciones de la obra y su idoneidad como fenómeno políticorevolucionario, consúltese Ek (1989).
} 
española y a la situación de los tiempos presentes. Justifican tal necesidad el profundo y sustancial cambio que ha experimentado, en todos sus aspectos, la vida nacional, como consecuencia de un cuarto de siglo de paz fecunda: las grandes transformaciones que se han ido produciendo en el ámbito internacional; las numerosas innovaciones de carácter técnico surgidas en la difusión impresa del pensamiento; la importancia, cada vez mayor, que los medios informativos poseen en relación con la información de la opinión pública, y, finalmente, la conveniencia indudable de proporcionar a dicha opinión cauces idóneos a través de los cuales sea posible canalizar debidamente las aspiraciones de todos los grupos sociales, alrededor de los cuales gira la convivencia nacional (BOE, 1966: 3310).

La conmemoración de los 25 años de Paz del régimen, expresión acuñada por el mismo Fraga, se festejaba con la aparición de una ley de prensa cuyo principio instaurador, según se publicaba en el BOE, "lo constituye la idea de lograr el máximo desarrollo y el máximo despliegue posible de la libertad de la persona para la expresión de su pensamiento", eso sí, con la idea "de acometer la edificación del orden que reclama la progresiva y perdurable convivencia de los españoles dentro de un marco de sentido universal y cristiano, tradicional en la historia patria" (BOE, 1966: 3310).

Dicha ley, en su artículo tercero, determinaba que la Administración no podía exigir censura previa ni consulta obligatoria a los editores, excepto en caso de declararse el estado de excepción y de guerra, pero, a su vez, preveía en su artículo cuarto que "la Administración podrá ser consultada sobre el contenido de toda clase de impresos por cualquier persona que pudiera resultar responsable de su difusión" (BOE, 1966: 3310). Aparecía así la consulta voluntaria a la que se sometían regularmente los editores a fin de evitar represalias posteriores, pues lo que no explicitaba el BOE era que la Junta de Censura podía requisar los ejemplares publicados que no habían pasado dicha consulta y tuvieran algún contenido "sospechoso" (Bacardí, 2012).

A esa censura voluntaria se acogieron las tres publicaciones de Dantons Tod que se realizaron en España en los últimos diez años de la dictadura, y cuyos expedientes se conservan en el Archivo General de la Administración de Alcalá de Henares. 


\section{La muerte de Danton: Aguilar, 1966}

En 1963 la editorial Aguilar ya había presentado a la censura obligatoria tres obras de teatro alemán de principios del XIX: Uriel Acosta, de Karl Gutzkow; La muerte de Danton, de Büchner; y el Don Juan y Fausto, de Charles Dietrich Grabbe. El Ministerio de Información y Turismo abría el expediente $n$. $^{\circ} 6942-63$ y se iniciaba el proceso habitual en estos casos, en el que el jefe de negociado adjudicaba a un censor la lectura de las piezas. El Lector no encontró objeción alguna en la circulación de los textos presentados, con lo cual la editorial madrileña podía libremente disponer de su publicación. Desconocemos los motivos por los cuales Aguilar no sacó en aquel momento las obras teatrales para las que había pedido permiso. Por aquellos años la editorial desarrollaba una intensa actividad con la publicación de numerosos volúmenes de obras completas y colecciones, especialmente de teatro, por lo que tal vez se le acumulara el material disponible que debía ser publicado.

De lo que no hay duda es que, aprovechando los aires ligeramente aperturistas, Aguilar decide en 1966 preparar un volumen sobre el teatro de la joven Alemania, dentro de su colección "Teatro de siempre", y así lo titula: Teatro de la Joven Alemania (1829-1846), traducido por Vicente Romero García. En él incluye Don Juan y Fausto, de Dietrich Grabbe; Urial Acosta, de Gutzkow; y La muerte de Danton, de Büchner, obras que ya habían pasado exitosamente la censura obligatoria en 1963, y añade Woyzeck del mismo Büchner ${ }^{2}$.

El 19 de noviembre de 1966 el representante de Aguilar S. A. Ediciones deposita en la Dirección General del Ministerio de Información y Turismo los seis ejemplares que exigía el artículo 12 de la Ley de Prensa e Imprenta para que fueran sometidos a la revisión de la consulta voluntaria. Se abría de este modo el expediente n. ${ }^{\circ}$ 7640-66.

Presentada la instancia para solicitar la impresión del volumen, el Jefe de Negociado de Circulación y Ficheros remitió al Lector los ejemplares para que fueran examinados. El censor se limitó a poner únicamente en el apartado de "Informe y otras observaciones": "Teatro.

\footnotetext{
${ }^{2}$ No eran las primeras traducciones al español de la obra de Büchner. Seis años antes, en 1960, había aparecido publicado en Buenos Aires un volumen con toda su producción dramática: La muerte de Danton. Leonce y Lena. Woyzeck, traducida por Alfredo Cahn para la argentina editorial Visión.
} 
Aut. 63", en referencia al género literario de la obra y a un expediente anterior, el n. ${ }^{\circ} 6942-63$, que ya había sido previamente autorizado.

De modo que con ese precedente, aprobado tres años antes, el 21 de noviembre de 1966, esto es, apenas dos días después del depósito de los ejemplares, el Jefe de la Sección de Lectorado, del que solo se consigna el apellido: Fajardo, resolvió que el volumen presentado a consulta voluntaria podía ser puesto en circulación, "vistos el informe de la Sección del Lectorado, las disposiciones vigentes y las normas comunicadas por la Superioridad". No había, pues, ningún inconveniente para que los 3.000 ejemplares que se tiraron pudieran ponerse a la venta en las librerías de la península.

De este expediente de censura sorprenden dos aspectos: la celeridad con que se resolvió el caso y su autorización. Es bien cierto que la existencia del precedente de 1963 aligeraba el proceso, que solía ser algo más dilatado por las medidas burocráticas que siempre se imponían. Posiblemente el desconocimiento del teatro alemán de principios del siglo XIX pudo ser un factor a su favor, pues bajo el nombre de la "Joven Alemania" (Das junge Deutschland) se aglutinaba un grupo de escritores revolucionarios cuyos escritos fueron prohibidos en los Estados de la Federación Alemana, según consta en el decreto de 10 de diciembre de 1835, por representar una literatura, en palabras del conde de Münch-Bellinghausen, "anticristiana, blasfema, pisoteadora consciente de toda moral, vergüenza y honradez" (Romero García, 1966: 10). Los presupuestos ideológicos de este grupo de escritores se fundaban en el rechazo del estado absolutista, de la iglesia ortodoxa, de las convenciones morales y sociales, y por su apuesta por el socialismo, la libertad de pensamiento y de la opinión pública. Cuesta creer que con todo ese ideario como trasfondo la publicación saliera a la luz sin ninguna objeción.

\section{La muerte de Danton: Gregorio del Toro, 1973}

El 10 de marzo de 1973 Gregorio del Toro, propietario de la editorial madrileña del mismo nombre, presenta en la Dirección General de Cultura Popular y Espectáculos, del Ministerio de Información y Turismo, la instancia cumplimentada y los seis volúmenes preceptivos para la revisión de la consulta voluntaria de una obra que lleva por título $L a$ 
muerte de Danton, en los que figuran como autores Georg Büchner y Emilio Romero Gómez.

Cumplidos, pues, los requisitos previos del depósito a la difusión, se abre el expediente de censura n. ${ }^{\circ} 3154-73$ y el Jefe de Circulación y Ficheros encarga al Lector . $^{\circ} 32$ el informe correspondiente. Dos días después, el censor concluye:

Se trata de la obra de teatro que actualmente se está representando en el Teatro Español de Madrid. La obra es del autor alemán Büchner y la adaptación es de Emilio Romero. El argumento es de sobra conocido ya que está basado en la vida de este personaje que es Danton y que tuvo un papel muy importante durante la Revolución Francesa. AUTORIZADA.

No entraremos a dilucidar si realmente el censor leyó la obra, aunque por la banalidad de los comentarios, intuimos que no, pero no importa. No le hacía falta leerla para autorizarla, por varios motivos. Por una parte, contaba con el precedente del expediente $n^{\circ}{ }^{\circ} 7640-66$ resuelto favorablemente y sin ningún reparo para la editorial Aguilar. Por otra parte, la obra se había estrenado el 14 de diciembre de 1972 (lo que significaba haber superado previamente la censura teatral) y continuaba en cartel, en el Teatro Español, un teatro oficial propiedad del Ministerio de Información y Turismo. Y un tercer factor, nada desdeñable, es que la adaptación había sido preparada por Emilio Romero, periodista y escritor de indiscutible e incuestionable filiación franquista y, en consecuencia, garante de que el texto contaba con una simpatía del régimen que el censor no se atrevió ni a cuestionar ${ }^{3}$.

La presencia de cuatro ministros y otros tantos altos cargos del gobierno el día del estreno era una evidente muestra del apoyo con que contaba el adaptador. Además, el Ministerio de Información y Turismo la incorporó al repertorio de Festivales de España, lo que significaba que salía de gira por toda la península, permiso este que el régimen no hubiera aceptado ante cualquier atisbo de duda.

\footnotetext{
${ }^{3}$ Emilio Romero (1917-2003) fue nombrado en 1945 Jefe de la Sección de Prensa en la Dirección General de Prensa y, poco después, asumió la jefatura de Orientación Política de la Prensa Española. En 1946 fue editorialista político y director entre 1952 y 1974 del diario Pueblo, que junto con Arriba, actuaba como portavoz del Movimiento.
} 
La pieza fue dirigida por Alberto González Vergel y la escenografía corrió a cargo de Francisco Nieva, que obtuvieron el premio de teatro "El espectador y la crítica 1972"4. La puesta en escena recibió toda suerte de halagos (a pesar de las tres horas y media de duración, tiempo que posteriormente se redujo), no así la adaptación, versión libre, recreación o co-creación de Romero -nombre con que los críticos se refirieron al trabajo del periodista-, que no estuvo exenta de polémica. Las primeras acusaciones, aparecidas en el semanario Triunfo, apuntaban a que Romero había falsificado las intenciones del autor:

El propio Romero facilitó ese rumor al afirmar que el sesenta por ciento de la obra era suyo y no de Büchner. Pero como las matemáticas no pueden expresar ni valorar la literatura, resultó a la hora del estreno que todo lo esencial era de Büchner y que el adaptador simplemente había desarrollado -con tino, tacto y respeto- ciertos aspectos de la tragedia, pues de una tragedia se trata. Dándole más papel a Robespierre quedó más equilibrada la información de la pugna entre el "incorruptible" y Danton (A. P., 1972, 80).

Esta misma idea reproduce López Sancho varios años después, durante la celebración del ciento cincuenta aniversario de la muerte del dramaturgo alemán, cuando al referirse a la adaptación de Romero, afirma: "Una colaboración al sesenta por ciento de Emilio Romero, que modifica el pensamiento de Büchner, aportándole la modernidad de una ideología posterior que, al mismo tiempo, lo contradice y lo completa" (1981: 81).

Otros, en cambio, pensaron que "ha sido un trabajo riguroso, largamente matizado" (Álvarez, Arriba, 16/12/1972), "su adaptación me parece espléndida, incluso respetuosa en exceso" (Prego, $A B C$, 16/12/1972), "lo que Emilio Romero ha suprimido o, mejor, acortado del original de Büchner, evidentemente sobraba; lo que ha añadido [...] enriquece el texto y sus posibilidades escénicas hasta límites insospechados" (Marquerie, Pueblo, 15/12/1972), "Emilio Romero ha hecho una adaptación hábil y dramáticamente sólida" (Monleón, Triunfo,

\footnotetext{
${ }^{4}$ La interpretación corrió a cargo de José María Prada y Javier Loyola (Danton), Germán Cobos (Robespierre), Berta Riaza (Lucila), Francisco Marsó (Desmoulins) y Roberto Martín (Saint-Just). La música fue compuesta por Cristóbal Halffter.
} 
23/12/1972), "la versión de Emilio Romero es espléndida, muy superior al original" $(A B C \text {, Sevilla, } 05 / 09 / 1973)^{5}$.

Romero en sus memorias recuerda las "dos grandes conmociones" de su vida como autor teatral, que no fueron otras que las dos adaptaciones libres de La muerte de Danton, de Büchner, y Galileo Galilei, de Brecht: "Ese era mi teatro y mis versiones fueron como me dio la gana" (1985: 162). A petición del entonces director general de Teatro, Mario Antolín, Romero aceptó preparar la versión con la condición de que le dieran plena libertad:

Se pedía mi versión o mi adaptación de esta tragedia, de texto y sustancia políticos intensos. Quise leer el texto auténtico alemán y después busqué otros. Entonces me puse a estudiar teatralmente, literariamente, políticamente, esta tragedia. Mis observaciones, resumidas fueron estas: Georg Büchner había vivido plenamente la expresión literaria de la obra; y había tratado ligeramente los aspectos históricos y políticos [...] Tenía aromas anticuados. Sentí entonces como mi obligación de adaptador enriquecer lo político e histórico, y aliviar lo literario deteriorado, porque, de verdad, lo que se había puesto en mis manos era el período más apasionante de la Revolución Francesa, como fue el Terror [...] Büchner no tenía mis ventajas en orden a la documentación completa de la Revolución Francesa. Estaba tan cerca de ella que no la pudo ver en su plenitud (1985: 163).

Romero quedó muy satisfecho del resultado y de la versión que preparó para el Español, y así lo confesó a sus amigos y colaboradores ${ }^{6}$. Esa versión fue muy libre, en palabras de García Ruiz y Torres Nebrera:

La obra de Büchner es una verdadera tragedia totalizadora, densa, que se vio demasiado aligerada en la versión del Español, utilizando un lenguaje demasiado llano, realista, funcional y con añadidos de matiz ideológico que, desde luego, fueron achacados a la pluma del adaptador

\footnotetext{
${ }^{5}$ Todas estas críticas pueden leerse íntegramente, además de en las publicaciones originales, en el prólogo a la edición de G. del Toro. No sorprende, pues, el tono laudatorio de todas ellas, ya que de otro modo no hubieran tenido cabida.

${ }^{6}$ A propósito de la faceta teatral de Emilio Romero, Amilibia, compañero del periodista en Pueblo, señala: "Me dijo una vez que solo estaba satisfecho de cinco funciones de las dieciocho que escribió y estrenó: Las ratas suben a la ciudad, El amante jubilado, Yo fui la amante del rey, y las versiones libres de La muerte de Danton, de Büchner, y de Galileo Galilei, de Bertolt Brecht" (2005: 168).
} 
[...] lo que suponía también una cierta manipulación en la concepción de los personajes sobre la idea inicial (2006: 21-22).

El 17 de octubre de 2013 se conmemoraron los 200 años del nacimiento de Büchner y el Instituto Goethe publicó en su página web un artículo sobre la difícil recepción del dramaturgo alemán en España ("Paz a las chozas...”). El autor ofrecía una opinión muy lúcida sobre la versión de Romero en el Español:

En el Teatro Español de Madrid se asistió a una desvergonzada manipulación del texto original, mutilación de diálogos, cuando no de escenas completas, se ensartaron temas y escenas de exclusiva cosecha de Romero y todo con el propósito de insistir en la inutilidad de cualquier cambio, de negar el carácter democrático de la revolución francesa y la de mandar un aviso de navegantes: en España debía quedar todo atado y bien atado. Nada que tuviera que ver con la obra de Büchner, quien seguía siendo un desconocido, incluso entre los iniciados.

En efecto, quien se acerque al texto de Romero poco podrá ver del espíritu de Büchner, pues el adaptador extrajo de la pieza aquello que le pareció más interesante y manipuló no solo los contenidos ideológicos (e incluso religiosos, prácticamente ausentes de su propuesta dramática), sino que convirtió en personajes principales a aquellos que le resultaron más atractivos. Si en la obra del dramaturgo alemán Danton, Desmoulins y su esposa (Lucila) ocupan el centro de la tragedia, Romero da protagonismo a Danton, a la mujer de este (Luisa) y a Robespierre, lo que implica no solo cambiar el eje en torno al cual gira la pieza, sino modificar el carácter de los personajes con tal de que el contraste entre Danton y Robespierre pase a primera línea. De este modo, Romero no duda en convertir al desalentado y cansado Danton de Büchner en un vividor y golfo insaciable, y transformar la pureza o virtud de Robespierre en un "desvío o flaqueza sexual" (Lázaro Carreter, Gaceta Ilustrada, 04/02/1973).

\section{La mort de Danton: Edicions Robrenyo, 1976}

E1 26 de noviembre de 1975, seis días después de la muerte de Franco, Salvador Serres, propietario de una pequeña editorial de Mataró, abierta apenas dos años antes con la intención de "divulgar cuantos estudios 
o textos puedan favorecer la afición teatral en sus múltiples aspectos" (expediente n. ${ }^{0}$ 9809/75) ${ }^{7}$, entregaba dos ejemplares de la obra La mort de Danton, de Georg Büchner, traducida por Carme Serrallonga, a la Delegación Provincial de Barcelona del Ministerio de Información y Turismo, para someterlos a la consulta voluntaria. La intención del editor era hacer una tirada de 200 ejemplares, según consta en la instancia presentada, una cantidad muy reducida que se usaba como recurso para conseguir el permiso deseado, especialmente en los textos traducidos al catalán. Era una manera de indicar que la obra no iba dirigida a un público mayoritario y, por tanto, el alcance del texto en catalán era controlable.

La muerte del dictador era reciente, la monarquía parlamentaria se auguraba como el futuro político de España, pero nadie sabía cómo se resolvería finalmente el devenir de la política española, ni si los aires aperturistas realmente llegarían ni a qué velocidad lo harían. Así que, siguiendo la vigente Ley de Prensa e Imprenta, Serres entrega La mort de Danton al funcionario de la delegación de Barcelona. Se abría así el expediente . $^{\circ} 13383-75$, en el que únicamente constaba como precedente la adaptación española de Emilio Romero, publicada por G. del Toro. No se hacía ninguna referencia a la edición madrileña de Aguilar (expediente n. ${ }^{\circ}$ 7640-66).

El 1 de diciembre de 1975 llega a Madrid, al delegado del Sr. Director General de Cultura Popular, la instancia presentada por Serres y los dos ejemplares que este había dejado en la sede de Barcelona. Ocho días más tarde, el Jefe del Negociado de Tramitación da fe de que la solicitud de consulta voluntaria ha llegado a la Dirección General de Cultura Popular del Ministerio de Información y Turismo de Madrid, y al día siguiente el Jefe de Negociado del Lectorado determina que el Lector $n .^{\circ} 17$ juzgue el contenido de la obra.

El informe emitido por el Lector n. $^{\circ} 17$ no se hizo esperar y el 9 de enero de 1976, concluye: "Autorizable con tachaduras". Tal vez el hecho de que fuera una obra histórica, situada cronológica y espacial-

\footnotetext{
${ }^{7}$ El expediente n. ${ }^{\circ}$ 9809/75 se abrió a propósito de la petición de censura voluntaria de La setmana tràgica, primera pieza teatral que publica Serres en su colección "Teatre de tots els temps". La obra no pasó la censura y estuvo retenida un año. Dado su contenido político, en el expediente se recoge una "Nota informativa sobre la empresa Salvador Serres Sanz", en la que se detallan las intenciones de la editorial y las simpatías comunistas de su propietario, si bien "observa buena conducta moral pública y privada".
} 
mente lejos de la realidad inmediata, contribuyera a que la obra no fuera considerada "peligrosa". Así se deduce de la idea que extrajo el censor tras la lectura de las galeradas, que sintetiza en los siguientes términos:

Los gerifaltes de la Revolución Francesa han guillotinado a la nobleza, pero el pueblo se queja de seguir tan hambriento como antes, Danton quiere acabar con las ejecuciones, y Robespierre le acusa de corrompido y le hace ejecutar.

Si uno se limita a esta lectura superficial, podría entender La mort de Danton como una pieza histórica que declara el infructuoso resultado del movimiento revolucionario, pero una lectura más atenta del texto deja asombrado incluso al lector actual, especialmente por la crudeza de algunas escenas, sus diálogos descarnados o por la falta de moral de una juventud que, apremiada por el hambre, exalta la prostitución. El Lector $n .^{\circ} 17$ podía haber respondido, a las preguntas que encabezan los formularios de los informes de censura, que el drama de Büchner atacaba a la moral, a la iglesia y hacía apología de las libertades. Pero no vio nada de eso y sus observaciones fueron las siguientes:

La obra es válida en líneas generales, y no ofrece inconvenientes de tipo político, ni socio-político. Aconsejaría una supresión en la p. 11 por equiparar a Cristo con el cuerpo de una mujer. También suprimiría una escena (págs. 28, 29 y 30) que pretende demostrar racionalmente la no existencia de Dios ${ }^{8}$.

La resolución de publicación del drama de Büchner llega el 13 de enero de 1976:

En contestación a su consulta de fecha de 9-12-75 acerca de la obra $L a$ mort de Danton de Georg Büchner se le comunica que no encuentra inconveniente para su edición, de la que deberá, en su día, constituir el depósito previo exigido por la vigente Ley de Prensa e Imprenta. Dios guarde a Vd. muchos años. Madrid 13/01/76.

\footnotetext{
${ }^{8}$ Las páginas que aparecen en esta cita se corresponden con las de las galeradas que Serres entregó en la Delegación del Ministerio. Quizá resulte ocioso señalar que el nombre de Cristo no se usa en la adaptación de Romero para compararlo con ninguna mujer y que la demostración racional de la no existencia de Dios se limita a la clasificación del género humano en creyentes y ateos.
} 
Con esta resolución Serres edita la obra y cuatro meses más tarde -el 12 de mayo de 1976-, entrega en depósito los seis ejemplares preceptivos en la Delegación Provincial de Barcelona. Un par de cosas habían cambiado desde que el editor de Mataró apareciera por primera vez en la Delegación, el 26 de noviembre de 1975. La primera de ellas está relacionada con la tirada: finalmente se editaron 2000 ejemplares (y no, 200 , como consta en el resguardo de consulta voluntaria y en la autorización del Ministerio). Y la segunda es que el texto que se publica no es idéntico al de las galeradas presentadas en el Ministerio, y no por la acción de la censura. Las modificaciones que se introdujeron atañían a cuestiones estilísticas y no de contenido. Las sugerencias del Lector $\mathrm{n}^{\circ}{ }^{\circ}$ 17 fueron totalmente desatendidas: la comparación del cuerpo de Cristo con el de una mujer (en realidad, la traducción utiliza el término genérico de "persona", o sea, que hizo una lectura errónea) continúa presente, exactamente igual que la demostración racional de la no existencia de Dios, al inicio del tercer acto.

De nada sirvió el peregrinaje de Salvador Serres de Mataró a la Delegación Provincial de Barcelona, ni los viajes de las instancias y de los ejemplares desde la capital catalana a Madrid, ni el trabajo del Lector n. ${ }^{\circ}$ 17, ni el del delegado del Ministerio, ni el del Jefe del Negociado, ni el de todo el aparato burocrático que se ponía en marcha cuando un ejemplar se sometía a la consulta voluntaria.

\section{Recapitulación}

En los últimos diez años del franquismo, Dantons Tod de Büchner se sometió en tres ocasiones a la consulta voluntaria, instaurada por Fraga en 1966, a partir de la promulgación de la Ley de Prensa e Imprenta. En todos los casos se abrió el expediente correspondiente, custodiados actualmente en el Archivo General de la Administración, en Alcalá de Henares.

A pesar del contenido revolucionario de la obra y el carácter transgresor de su autor, la pieza consiguió salir exitosa del proceso censor. En primer lugar, seguramente, porque en la edición de Aguilar (1966) quedaba medio oculta en el volumen colectivo publicado bajo el rótulo de Teatro de la Joven Alemania (1829-1846).

En el segundo caso, G. del Toro (1972) publicó la adaptación de Emilio Romero, una adaptación polémica en la que solo sobrevivió lo 
que el periodista consideró destacable y no censurable. Cabe pensar que una lectura sesgada de la obra, como la que se hizo, podría no desagradar a la mentalidad franquista, pues el reconocimiento explícito de Danton del fracaso de la revolución, de la inutilidad de la muerte de la nobleza, de la falta de efectividad de una revolución que no había resuelto los desajustes sociales ni había calmado el hambre del pueblo... podrían ser argumentos incluso aleccionadores sobre la inutilidad de la revuelta popular y, en consecuencia, sobre el infructuoso resultado del movimiento revolucionario.

En el tercer caso, la traducción se hizo al catalán. Aun después de Franco, el régimen daba sus últimos coletazos y Serres, el editor, se ajustó a la censura voluntaria, por lo que pudiera pasar. Las sugerencias que se le hicieron fueron consideradas simplemente como lo que eran, "sugerencias", y Serres publicó el texto tal como Carme Serrallonga, la traductora, fiel al original, se lo había entregado.

\section{Bibliografía}

A. P. 1972 (23 de diciembre). Una adaptación polémica y una farsa muy divertida. Blanco y Negro, p. 80.

$A B C .1973$ (5 de septiembre). Se agotaron las localidades para "La muerte de Danton", representada por la compañía del Teatro Español. $A B C$, p. 49. Amilibia, Jesús M. 2005. Emilio Romero. El gallo del franquismo. Madrid: Ediciones Temas de Hoy.

Bacardí, Montserrat. 2012. La traducció catalana sota el franquisme. Lleida: Punctum.

BOE. 1966. Ley 14/1966, de 18 de marzo, de Prensa e Imprenta, 67, 33103315.

Ek, Sverker. 1989. Avatars d'un mythe. La mort de Danton, drame de Georg Büchner. Annales historiques de la Révolution française, 227, 177-292.

García Ruiz, Víctor \& Torres Nebrera, Gregorio. 2006. El teatro español en el último quinquenio del franquismo. En Historia y antología del teatro español de posguerra: 1971-1975, vol. VII. Madrid: Editorial Fundamentos, 11-158.

Julio, Teresa. En prensa. La mort de Danton, de Büchner, o l'eficiència de la censura en la traducció de Carme Serrallonga.

López Sancho, Lorenzo. 1981 (19 de febrero). El autor de Woyzeck y el impulso romántico como raíz de modernidad. $A B C$, p. 81 .

Muñoz Cáliz, Berta. 2005. El teatro crítico español durante el franquismo visto por sus censores. Madrid: Fundación Universitaria Española. 
"Paz a las chozas, guerra a los palacios": La desigual suerte de Georg Büchner en España, http: //www.goethe.de/ins/es/es/lp/kul $/ \mathrm{mag} / \mathrm{lit} /$ gen/11663353.html. [Acceso 12/12/2014].

Romero, Emilio. 1985. Tragicomedia de España. Unas memorias sin contemplaciones. Barcelona: Planeta.

Romero García, Vicente. 1966. Estudio preliminar a La muerte de Danton, Teatro de la joven Alemania. Madrid: Aguilar.

Vidal, Josep A. 1976. Una sortida a l'exterior. Publicacions de teatre. Serra d'Or 203, agosto, 33-34.

\section{Fuentes primarias}

Büchner, Georg. 1966. La muerte de Danton, en Teatro de la joven Alemania. Madrid: Aguilar. [Traducción de Vicente Romero García].

Büchner, Georg \& Romero, Emilio. 1973. La muerte de Danton. Madrid: Gregorio del Toro. [Traducción de Emilio Romero].

Büchner, Georg. 1976. La mort de Danton. Mataró: Robrenyo. [Traducción de Carme Serrallonga].

\section{Expedientes consultados}

Expediente de censura n. ${ }^{\circ}$ 6942-63. Büchner, Georg. La muerte de Danton Aguilar (1963). Archivo General de la Administración. Alcalá de Henares.

Expediente de censura n. ${ }^{\circ}$ 7640-66. Büchner, Georg. La muerte de Danton Aguilar (1966). Archivo General de la Administración. Alcalá de Henares.

Expediente de censura n. ${ }^{\circ}$ 3154-73. Büchner, Georg y Romero, Emilio. La muerte de Danton. Gregorio del Toro (1973). Archivo General de la Administración. Alcalá de Henares.

Expediente de censura n. ${ }^{\circ}$ 9809/75. Pasqual, Lluís. La semana trágica. Edicions Robrenyo (1975). Archivo General de la Administración. Alcalá de Henares.

Expediente de censura n. ${ }^{\circ}$ 13383-75. Büchner, Georg. La mort de Danton. Edicions Robrenyo (1975). Archivo General de la Administración. Alcalá de Henares. 
